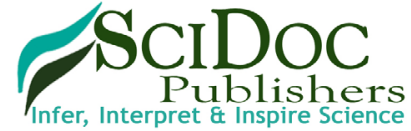

\section{Environmental Impact on Processing Quality of Wheat Grain}

International Journal of Food Science, Nutrition and Dietetics (IJFS)

ISSN:2326-3350

Review Article

Melaku Tafese Awulachew*

Department of Food Science and Nutrition Research Process, Ethiopian Institute of Agricultural Research, Kulumsa Agricultural Research Center, Assela, Ethiopia.

\title{
Abstract
}

Improvement of end-use quality in wheat (Triticum aestivum L.) depends on thorough understanding of the Influences of environment, genotype, and their interaction. This publication provides to determine the general principles underlying how the environment affects wheat quality, facilitate further investigations of the environmental mechanisms that affect grain quality specially protein in contentand thereby achieve good processing quality and also, it provides information on the environment effects on wheat quality attributes that are important to achieving this goal. There is a continuing need for wheat quality research to maintain existing standards, to introduce new and updated information and to identify novel traits, markets and end-use products. All this information must be available to wheat breeders so that new wheat varieties target the intended end-use of growers, marketers and consumers. Wheat is known to be one of the most important agricultural crops throughout the world and hence, the objective of this review was to assess and/or to determine the general principles underlying how the environment affects wheat quality, facilitate further investigations of the environmental mechanisms that affect grain protein in content, and thereby achieve good processing quality. Environmental variables have important effects on wheat grain protein accumulation and processing quality, although wheat quality is a genotype-dependent trait. Moderately high temperature, proper soil moisture (resulting from rainfall and irrigation), and sufficient solar radiation may improve wheat quality. Some ecological factors, including soil physiological and chemical properties and geographic latitude, can also affect wheat quality. Wheat quality may be improved by breeding elite varieties, improving crop/farming management practices and exploiting the synergism between genotype and the environment. In addition to the yield, the grain quality of wheat is central to the well-being of humans. Because of its high grain protein in content, wheat is extensively applied in many foods and industrial uses. Currently, increasing grain quality is becoming a widely discussed topic in crop sciences. Those, Wheat quality is directly affected by diverse environmental factors. However, the mechanisms of environmental effects are not fully elucidated, and experimental results are often inconsistent between regions or over years. More importantly, this paper provides a number of potential strategies to increase the grain protein in content and protein-based grain processing quality.

Keywords: Environmental Factors; Processing Quality; Improvements; Wheat Varieties.

Abbreviations: GrADS: Grid Analysis and Display System; HMW-GS: High-molecular-weight gluten in subunits; LMWGSs: Low molecular weight glutens subunits; MATLAB: Matrix Laboratory; NCL: NCAR Command Language; DMT: Daily mean temperature; AMT: Annual mean temperature; AMMI: Additive main effects and multiplicative interaction; DVOT: Diurnal variation of temperature; FN: Falling number; FV: Final viscosity; G×E: Genotype by environment; GPC: Grain protein content; PV: Peak viscosity; QTL: Quantitative trait loci; SDS: Sodium dodecyl sulfate; ST: stability time; SV: Sedimentation value; TNOSH: Total number of sunshine hours; WGC: Wet gluten content.

\section{*Corresponding Author:}

Melaku Tafese Awulachew,

Department of Food Science and Nutrition Research Process, Ethiopian Institute of Agricultural Research, Kulumsa Agricultural Research Center, P.O.box:489, Assela, Ethiopia. Tel: +251924621018

E-mail: Melakutafese12@gmail.com

Received: October 14, 2019

Accepted: November 14, 2019

Published: November 28, 2019

Citation: Melaku Tafese Awulachew. Environmental Impact on Processing Quality of Wheat Grain. Int J Food Sci Nutr Diet.. 2019;S1:02:001:1-8. doi: http://dx.doi.org/10.19070/2326-3350-SI02-01001

Copyright: Melaku Tafese Awulachew ${ }^{\circ}$ 2019. This is an open-access article distributed under the terms of the Creative Commons Attribution License, which permits unrestricted use, distribution and reproduction in any medium, provided the original author and source are credited. 


\section{Introduction}

Wheat (Triticumaestivum L.) is the most important cereal crop and staple food of about two billion people around the world [14]. It is one of the important grain crops produced worldwide. Commercially cultivated wheat is basically of two types, i.e. durum wheat (Triticum turgidum) and bread wheat (Triticum aestivum), which differ in their genetic makeup, adaptation and uses. According to the FAO, 2005 report, about 620 million metric tons of wheat was produced from 217 million hectares in the year 2005/06 with an average yield of 2.85 metric tons per hectare [17]. Wheat is grown on larger area than any other crop and its world trade is greater than for all other crops combined. Its world trade is greater than for all other crops combined. It is easily stored and transported [52]. Wheat grain is an excellent staple food with numerous nutritional and health-beneficial compounds [33, 73]. The priority has now gradually shifted to the improvement of processing quality, due primarily to the increase in food diversity and market demand $[4,27]$. Consequently, improving wheat grain protein content (GPC) and processing quality has become one of the main breeding goals $[27,37,56,71]$. However, our knowledge of this aspect is still limited; thus, programs for this aim are hampered mainly by an unawareness of the strong influence of environment on grain quality [37]. Numerous studies have been carried out to evaluate the effects of environmental diversity on wheat quality. This research has shown that the majority of GPCs and other quality traits can be greatly affected by a host of environmental factors, with growing zone and climatic variables showing the largest effects $[32,50,56,58]$. These results parallel the findings of some international agronomists who also stressed the influences of climatic variables on wheat quality [23, 49]. In recent years, the quality of the environment has been worsening because of changes in climatic variables and the composition of the atmosphere. Some scientists have predicted an increase in global temperature of between $1.5^{\circ} \mathrm{C}$ and $5.5^{\circ} \mathrm{C}$ in the next 50-75 years. Thus, in many parts of the world's wheat growing areas, temperatures during grain filling may reach $40^{\circ} \mathrm{C}$ and then exert a severe heat stress to the moderate-climate crop. At various sites across the Chinese wheat belts, maximum temperatures of over $35^{\circ} \mathrm{C}$ occur more commonly during grain filling. Moreover, a $3-4^{\circ} \mathrm{C}$ increase in annual mean temperature (AMT) has been predicted in China by the end of the $21^{\text {st }}$ century [26]. Many changes, such as $\mathrm{CO}_{2}$ enrichment, precipitation amount, timing and uneven distribution, are likely to make the global environment poorer and exert severe influence on crop quality in the future [28, $33,26]$. Additionally, a directory that includes the regularization of wheat production area with well-characterized production environments could be used to plant wheat cultivars with targeted end-uses. Proteins are the most important component of wheat grains governing the technological and rheological properties of flour and are closely associated with end-use quality [76]. GPC, particularly gluten content, is positively correlated with Zeleny sedimentation value (SV), and stability time (ST) and is thus regarded as an important index for wheat quality [50, 62]. Wheat breeders routinely use milling and baking quality evaluations as important selection criteria. Breeding programs, however, have in adequate resources to evaluate quality characteristics of large numbers of lines grown across multiple environments. Hence, breeders have little information on quality variation attributable to differential responses of genotypes to Environmental conditions In this study, we provide a comprehensive compilation of existing data and some potential recommendations with the objectives of evaluating the relationship between environmental factors and wheat quality and thus accelerating the improvement of wheat quality.

\section{Material and Methods}

\section{Methods}

This literature review was formulated through literature searches using Science direct. The following keywords were used:" Environmental factors, processing quality, Improvements, wheat varieties". The logical term operant and was used in the search of items to match keywords.

\section{Defining Breeding Targets}

A good wheat variety must meet the needs of all in the wheat value chain. That is, from the farmer, to the miller, to processors and manufacturers through to the consumer. Wheat breeders need to understand the needs of all in the value chain and use the available genetics and quality testing capability to develop new varieties that will produce the high quality, attractive and nutritious bread, cake and pastry products demanded by consumers. Successful wheat breeding is about having clearly defined and achievable targets. Agronomic attributes like plant height, straw strength, ease of threshing and maturity optimum for the target production region are essential components of all varieties. A thorough knowledge of the environment of the target production region is critical, as this determines yield potential, the range and type of challenges the crop will experience from biological threats such as pests and diseases and soil and environmental stresses. Importantly, it also determines the quality type that can be reliably and profitably grown in that region. Rainfall sets yield potential and along with the onset of summer temperatures determines the quality types that can be reliably and profitably grown. Other major environmental influences effecting yield potential and quality are soil type, high temperature events during grain development and the occurrence of frost events during vegetative growth and or at flowering time. The interplay between rainfall distribution and temperature, in the presence of susceptible varieties, creates the conditions for disease epidemics, and Ethiopian breeders have to contend with a formidable list of diseases including, stem, leaf and stripe rust, yellow spot, septoriatritici blotch, septorianodorum blotch, crown rot, take-all, common root rot, and 3 different soilborne nematodes. Most diseases have an adverse impact on grain, processing and end-product quality.

\section{Grain Quality and Quality Improvement}

The rapid increase in the world population demands parallel increases in food production, particularly of wheat. However, in order to preserve the environment and the present natural resources, further increases in global wheat production must come mainly from enhancing the yield potential of new wheat varieties and not from expanding the wheat production area.

Increasing yield potential without affecting negatively the quality of the grain is difficult, mainly because increases in grain yield are generally accompanied by a decrease in the grain's protein content, which is strongly associated with bread-making quality. 
Therefore, wheat breeders need to give grain quality aspects the same importance that they give to yield potential and disease resistance. Research objectives that are important for breeding programs developing wheat cultivars targeted to specific food markets include: understanding the genetic control of specific grain components; understanding the relationship between grain composition and processing qualities; achieving rapid identification and manipulation of quality-related traits based on the use of reliable, fast, low-scale quality testing methodology.

Grain hardness: Grain hardness is determined by the way components are packed in the endosperm cells and refers to the resistance the grain opposes to being fractured and to being reduced to fine whole meal flour or to fine endosperm particles (semolina or refined flour). Grain hardness is a grain quality trait associated with the milling properties of wheat [42] and with the baking quality of the resulting milling products. Milling times, milling energy requirements and the level of starch damage produced in the milled flour are all influenced by grain hardness. Hard wheats require longer milling times and more milling energy, and produce a larger amount of damaged starch.

The genetic control of grain hardness is still unknown. Although grain hardness has been associated with a $15 \mathrm{KD}$ protein attached to the surface of the starch granule, starch from soft wheats tends to have more of this protein than does starch from hard wheats $[19,20]$. The actual role of the $15 \mathrm{KD}$ protein (which is controlled by a gene on chromosome 5DS) on determining grain hardness is still not well understood [20]. Rapid small-scale methods (based on grinding time, grinding volume, or particle size distribution) used to determine grain hardness make it relatively easy to screen for hardness as early as the F3 generation. Near infrared reflectance and transmittance (NIR, NIT) analysis of the particle size distribution of whole grain flour or analysis of the intact grain samples are particularly fast and useful in early generation screening.

Starch: Native starch, which is the main component of the wheat grain (70 to 75 percent dry weight), shows little influence on the functional properties of wheat flours used in bread, cookie and cake making. Damaged starch (mechanically damaged during flour milling), however, by exposing its components (amylose and amylopectin) to interact with other constituents of the baking formula, influences importantly the water absorption and fermentation time requirements of bread-making doughs, as well as the staling and crumb textural properties of bread. Some small amount of damaged starch is desirable in bread-making flours but highly undesirable in cookie- and cake-making flours, as it may reduce considerably the expansion capacity of cookie doughs [41] and cake batters during baking. This is the reason why the cookie and cake industries use soft wheat flour, which has a minimum, if any, of mechanically damaged starch and, consequently, low flour water absorption. The swelling and pasting properties of native starch influence, on the other hand, the eating quality of wheat flour noodles, particularly white noodles, which are characterized for being smooth and soft but slightly elastic [8, 35, 43]. High starch swelling and desirable noodle softness (low firmness) have been associated with the absence (presence of Null4A) of the granule bound starch synthase (GBSS) protein controlled by genes on chromosome 4A. Other starch- and protein-related factors also influence starch swelling and noodle softness, and may mask the quality effects of Null4A. Thus screening for Null4A may not be effective to improve starch properties for noodle making. The Amylograph/Viscograph and more recently the Rapid ViscoAnalyser (RVA) are used to obtain a complete profile of starch pasting properties. While the first requires a large sample size and a considerably long testing time, the RVA requires a 3 to $4 \mathrm{~g}$ sample and only a few minutes to reveal the pasting profile of the tested material. Therefore, the RVA is now considered a rapid test suitable for the early selection of wheat lines possessing desirable starch pasting viscosity for noodle making ([8]; Panozzo and McCormick, 1993).

Proteins: Grain protein content in wheat varies between 8 and 17 percent, depending on genetic make-up and on external factors associated with the crop. A unique property of wheat flour is that its insoluble protein forms, when in contact with water, a viscoelastic protein mass known as gluten. Gluten, comprising roughly 78 to 85 percent of total wheat endosperm protein, is a very large complex composed mainly of polymeric (multiple polypeptide chains linked by disulphide bonds) and monomeric (single chain polypeptides) proteins known as glutenins and gliadins, respectively [40]. Glutenins confer elasticity, while gliadins confer mainly viscous flow and extensibility to the gluten complex. Thus, gluten is responsible for most of the viscoelastic properties of wheat flour doughs and is the main factor dictating the use of a wheat variety in bread and pasta making. Gluten viscoelasticity, for end-use purposes, is commonly known as flour or dough strength. Variations in grain protein content may significantly influence the dough strength properties of a wheat variety. Quantity alone, however, cannot always explain quality differences among wheat cultivars. Therefore, protein quality, in terms of the polymeric/monomeric protein ratio and the molecular size of the protein polymer (determined by the presence of specific glutenin subunits), is also important [62]. Wheat flour contains roughly the same amounts of glutenins and gliadins, and the unbalance of the glutenin/gliadin ratio may change its viscoelastic properties. The glutenin fraction is, however, the major protein factor responsible for variations in dough strength among wheat varieties [18]. Recently confirmed this; they observed that most of the variation in dough strength parameters was explained by the amounts of soluble and insoluble glutenin. The Zeleny and the sodium dodecyl sulphate (SDS) sedimentation tests [3] can be used to obtain a semi-quantitative estimation of the amount of glutenin (or indirectly, of general gluten strength). These tests, which are based on the expansion of mainly glutenins (also known as gel proteins) in lactic acid or SDS/lactic acid solution, are currently the most rapid and reliable single small-scale tests [62]. These tests are widely used to screen early generation wheat lines in relation to their general gluten strength type (strong to weak).

Minor grain constituents: Lipids, pentosans, soluble proteins and other minor grain constituents also play a role in determining wheat flour quality. Their effect on flour and dough functionality can be corrected, generally, by making adjustments to formulas (e.g. use of additives or improvers) and to the baking process. Therefore, from the grain quality improvement point of view, they are not considered major ones. Grain and non-grain (environment, growing conditions and diseases) factors interact to make the issue of quality rather complex. In spite of this, applying selection pressure at the segregating stages using rapid smallscale quality tests (NIR analysis of grain hardness and protein, SDS sedimentation, SDS-PAGE analysis of gluten proteins and RVA analysis of starch) results in significant improvements on 
the general quality characteristics of the wheat germplasm. The development of advanced lines possessing more specific desirable quality attributes can be achieved by screening wheat advanced lines for dough viscoelasticity (with the Extensigraph or the Alveograph), for dough mixing properties (with the Farinograph or the Mixograph) and for end-use quality (bread, cookie, pasta, etc., using laboratory-scale methods). Applying quality selection pressure at both the segregating and advanced stages should allow breeders to develop wheat varieties that are as productive as cropping and environmental conditions permit while possessing the quality attributes required by the baking industry.

\section{Biotechnology and the Improvement of End-use Quality}

Novel biotechnology techniques have opened the possibilities of investigating the basic genetic and biochemical aspects of individual protein subunits and of other molecules contributing to the end-use quality of wheat. For example, experiments in which individual HMWG subunits (synthesized from DNA cloned in Escherichia coli) were incorporated into wheat flour showed that dough strength can be enhanced by increasing the amount of polymeric subunits in the gluten complex $[5,6,7]$. These results prompted some researchers to generate glutenin genes and DNA clones to explore the possibility of improving wheat protein quality through genetic transformation $[1-3,10]$. Genetic transformation combines embryo culture with direct insertion (bombardment of gold pellets carrying DNA is an efficient technique) of specific genes to transform the recipient embryos in relation to specific traits. This is achieved in one single generation. Some examples of traits that can be modified include: disease and pest resistance, the nutritional (e.g. essential amino acids) and utilization value (e.g. changes in the functionality of proteins and starch) of crops and the suppression of undesirable gene expression (by introducing antisense genes), such as that promoting the increase of hydrolytic enzymes associated with pre-harvest grain sprouting, or that controlling the synthesis of undesirable molecules such as secalin proteins from rye in $1 \mathrm{~B} / 1 \mathrm{R}$ translocation wheats [9]. Wheat has been transformed in relation to HMWG subunit composition and starch composition; however, the level of expression of the inserted genes and their contribution to quality in wheat advanced lines ready for varietal release are still to be determined [2, 9, 10]. Molecular marker technology is also expected to increase efficiency and speed up the process of combining specific genes in new breeder's germplasm. Instead of selecting progeny of new crosses by determining gene action (for example, presence of specific HMWG subunits or determination of their quality effect), marker-assisted selection is expected to allow breeders to select directly germplasm carrying the desirable gene(s). Marker-assisted selection has been very useful in selecting plants carrying genes associated with resistance to pests and diseases, but has not proved yet as a better, more efficient alternative to the traditional chemical and biochemical small-scale methodology used in screening for quality breeder's wheat segregating germplasm.

\section{Discussion}

\section{Influence of Environmental Factors on Wheat GPC and Processing Quality}

Solar radiation: Sunshine duration affects grain quality throughout the growth season of wheat (Table 1). The total number of sunshine hours (TNOSH) during grain filling was linearly correlated to the GPC, WGC, flour FN, and paste properties $[45,66,71,72]$ In addition, illumination intensity may affect GPC because low illumination intensity increases GPC via differential effects on photo assimilation and protein accumulations in the grains [67].

Soil moisture regime: Wheat is widely grown in semi-arid areas, where large fluctuations occur in the amount and frequency of rainfall over years, which provides varying soil moisture regimes. The optimum soil water status can increase the availability of nutrients to the crop because it increases root growth and the mass flow of water and therefore increases plant nitrogen uptake. Thus, proper water conditions at the late wheat growth stages and grain ongenesis enhance both grain yield and quality $[65,75]$. Mild water deficit during maturation is essential for increasing GPC, WGC, peak viscosity (PV), FN, final viscosity (FV), and the contents of some amino acids, such as lysine, histidine, and glycin. However, this deficit could be achieved at the cost of reductions in grain yield and the contents of amylose, starch, and lipids [11, 25, $65,75]$. Thus, droughts tend to promote grain protein deposition over starch accumulation $[16,66]$ postulate that drought during grain filling often prevents starch accumulation in the grain by hindering the conversion of sucrose into starch but has less effect on protein biosynthesis. Thus, it appears that regions under rainfed conditions offer a potential opportunity for the production of wheat quality at acceptable levels.

Temperature: Grain quality is affected by the temperature regime variations in different growth locations (Table 1). The mechanisms underlying which temperature regimes influence GPC have been postulated: (a) Moderately high soil temperature promotes nitrogen uptake from the soil and nitrogen retrains location from the vegetative parts to the grain; and (b) The

Table 1. Correlation Coefficients between Climate Variables and Processing Quality Characteristics During the Period From Anthesis to Maturity [32, 48].

\begin{tabular}{|c|c|c|c|c|c|c|}
\hline Climate variables & GPC (\%) & SV (ml) & WGC (\%) & Gluten index & FN (s) & Paste extensibility \\
\hline Daily accumulative temperature & 0.324 & $0.449^{*}$ & 0.158 & 0.266 & - & $0.445^{*}$ \\
\hline Daily average temperature $\left(>22^{\circ} \mathrm{C}\right)$ & $-0.449^{*}$ & -0.37 & $-0.453^{*}$ & -0.03 & - & $-0.663^{* *}$ \\
\hline Diurnal temperature difference & $0.48^{* *}$ & $0.32^{*}$ & $0.33^{*}$ & - & $0.68^{* *}$ & - \\
\hline Total rainfall & $-0.30^{*}$ & -0.09 & $-0.34^{*}$ & - & $-0.46^{* *}$ & - \\
\hline Total sunshine $(\mathrm{h})$ & 0.299 & $0.445^{*}$ & 0.116 & 0.283 & $0.59^{* *}$ & $0.422^{*}$ \\
\hline
\end{tabular}

$*$ and $* *$ are significant at the 0.05 and 0.01 probability levels, respectively. 
optimal temperature for protein biosynthesis is far higher than that for starch biosynthesis $\left(15-20^{\circ} \mathrm{C}\right)$ [31]. Therefore, moderately high temperatures during grain filling may stimulate grain protein synthesis and protein remobilization from vegetable organs to grains but may reduce photosynthesis and hinder both the conversion of sucrose into starch and the translocation of carbohydrate reserves from vegetative organs to the grain $[12,23]$, thereby increasing GPC. However, (c) daily maximum temperatures exceeding $32^{\circ} \mathrm{C}$ would reduce the duration of grain ongenesis, result in a change in protein composition, produce shriveled grains containing a higher proportion of bran and thus reduce the wheat quality $[4,44,68]$.

Precipitation: Although its effects on grain quality vary by location, precipitation is commonly considered to be negatively correlated with GPC and grain-processing quality (Table 1).

Soil type: GPC, WGC, and SV are higher in wheat grown in fluvo-aquic soil than in wheat grown in brown soil, black soil, or cinnamon soil [58]. Weak- and medium-gluten wheat varieties grown in loam soil express higher GPCs than when grown in clay and sandy soil; in contrast, strong-gluten wheat cultivars grown in clay soil produce higher GPCs than when grown in loam and sandy soil [24]. All of the weak- and strong-gluten wheat cultivars grown in clay soil developed better $\mathrm{FN}$ and higher flour extraction rates than those grown in sandy soil and loam soil [25]. Generally, GPC and WGC increase with increasing soil viscosity, likely because of the higher holding capacity of the soil water [22]. However, the genotypic responses to soil type are often inconsistent in terms of wheat quality [48].

Latitude: As a long day plant growing in a temperate zone, wheat has a relatively wide adaptive range of environments and can grow over a wide range of latitudes from $18^{\circ} \mathrm{N}$ to $50^{\circ} \mathrm{N}$ in China. In regions between $31^{\circ} 51^{\prime}$ and $45^{\circ} 41^{\prime} \mathrm{N}$, latitude is positively correlated with GPC ( $\mathrm{r}=0.5136)$, which increases by $0.442 \%$ with a $1^{\circ}$ increase in latitude [39]. In addition, PV, trough viscosity, breakdown, and FV tend to increase with increasing latitude [66, 71]. A five-year analysis of the quality characteristics using 2,500 grain samples that were obtained across Zones I-IV suggests that GPC and processing quality, such as loaf volume and loaf score, increase from low to high latitudes, although the withinyear variations across these zones are not highly consistent [30]. Based on these data, one hypothesis is that in higher latitudes, the environment appears to be more favorable for good-quality wheat production [70]. The interaction of latitude and elevation was negatively correlated with GPC, WGC, FN, and Zeleny SV because of the longer growth period in higher-elevation regions [63]. These exceptions suggest that environmental specialtyis closely associated with grain protein accumulation. In summary, latitude exerts considerable effects on wheat GPC and processing quality. However, these studies have not isolated the effects of latitude from other environmental factors, such as temperature, precipitation, sunshine time, soil type, and soil fertility. In terms of geography, latitude reflects a comprehensive influence of these environmental factors. The reasons for the specific effects of latitude on wheat quality remain speculative.

Interactions of $G \times E$ and between environmental variables: The interactions of $\mathrm{G} \times \mathrm{E}$ significantly influence all quality traits, including GPC, WGC, FN, SV [46], glutenin and gliadin contents, glutenin/gliadin ratio [32], test weight, mixing development time, and the Rapid Visco-Analyzer parameters [71]. The additive main effects and multiplicative interaction (AMMI) model has been used to evaluate wheat grain quality using a number of genotypes grown at multiple sites, and the results are highly consistent with the above findings $[31,50]$. Moreover, the interactions among environment, genotype and sowing time greatly influence the indicators of wheat end-use quality (Table 2) [46]. The stepwise multiple regression analysis has indicated that GPC in highprotein grain was mainly determined by a high DVOT $(>5 \%)$ from heading to maturity. However, when the DVOT was less than $5 \%$ from heading to maturity, GPC was mainly determined by the interactions of mean temperature and sunshine hours. For medium-protein cultivars, GPC was mainly determined by sunshine duration from heading to maturity, whereas for lowprotein varieties, it was determined by the interactions among mean temperature, sunshine hours and precipitation [45].

\section{Strategies to Improve Wheat Quality}

Improvements in wheat varieties: The wheat variety is the most important factor influencing the wheat quality parameters $[22,29]$. Therefore, the careful selection from and appropriate use of the currently available genotypes may be an effective way to improve wheat quality [71]. The traditional cross breeding of new cultivars is considered ideal for enhancing wheat quality and adaptability to environmental variations [36]. Thus, the selection of crossing parents that confer desirable quality attributes and a combination of good-quality genes will lead to a considerable improvement in wheat quality [71]. Then, breeding programs will have to include efforts to understand the $G \times E$ interactions $[29,71]$. More than $40 \%$ of progenies have a higher GPC than their parents $[36,38]$. Therefore, the selection of some goodquality strains from the progenies of somaclonal variation may be efficient in improving wheat quality. Most importantly, genetic modification plays a crucial role in quality wheat production. The better usage of genetic potentials, such as high sprouting resistance and early maturity to avoid high temperatures at the late stages of grain filling, should be favored for adaptation to different environments.

\section{Crop/farming management practices:}

\section{Fertilization}

Grain protein quality is positively correlated with nitrogen concentration, even at a soil depth of $1.8 \mathrm{~m}(\mathrm{r}=0.82)$ [34]. Thus, it is important to develop rational practices for nitrogen application for high wheat quality. The application of an adequate amount of soil nitrogen fertilizer at the early stages is necessary to attain good grain quality [21]. Otherwise, topdressing at the booting to anthesis stages could increase GPC and glutenin content and therefore improve the wheat's processing quality [50] because topdressing nitrogen partly mitigates the heat stress-induced reductions in the expression of protein, wet gluten, gliadins, glutenins, HMW-GS, and LMW-GS [73]. Nitrogen applications later in the season were more effective than earlier applications in improving protein quality [60] partly because a later fertilization can compensate for the negative effect of excessive precipitation on protein accumulation and processing quality $[73,75]$. However, highly excessive nitrogen applications significantly deteriorate the wheat quality by both decreasing HMW-GS expression [51] and increasing the wheat's sensitivity to DMT during grain filling [22]. 
In addition, $\mathrm{P}$ (ca. $150 \mathrm{~kg} \mathrm{P}_{2} \mathrm{O}_{5} \mathrm{ha}^{-1}$ ) and $\mathrm{K}$ (ca. $100 \mathrm{~kg} \mathrm{~K} \mathrm{O} \mathrm{ha}^{-1}$ ) improve wheat quality. The combination of $\mathrm{N}, \mathrm{P}$, and $\mathrm{K}$ is most beneficial for the expression of GPC, WGC, and SV, followed by $\mathrm{N}$ plus $\mathrm{K}, \mathrm{N}$ plus $\mathrm{P}, \mathrm{N}, \mathrm{P}$ plus $\mathrm{K}, \mathrm{K}$, and $\mathrm{P}[70,74]$. In fluvoaquic soil with a moderate fertility, the addition of $\sim 120 \mathrm{~kg} \mathrm{~K} \mathrm{O}_{2}$ $\mathrm{ha}^{-1}$ preferentially increases the GPC, WGC, and FN [59], and when combined with nitrogen fertilizers, the $\mathrm{K}_{2} \mathrm{O}$ increases the wheat's dough extensibility and flour extension area because of the increased dough elastic [74] in strong-gluten cultivars. In medium loam with a higher fertility, a total of $60 \mathrm{~kg} \mathrm{~S} \mathrm{ha}^{-1}$ and $240 \mathrm{~kg} \mathrm{~N} \mathrm{ha}{ }^{-1}$ applied equally during the planting and shooting stages improves dough extensibility, dough rheological properties, and other processing qualities [64]. Zn can interact with grainfilling temperatures and alter the wheat's protein composition. Increasing $\mathrm{Zn}$ nutrition can enhance the proportions of gliadin and sodium dodecyl sulfate (SDS) extractable polymeric GPC in wheat under heat stress [47].

\section{Irrigation schedule}

The accumulation of protein components (particularly gliadins and glutenins) in the grains was sensitive to the soil moisture regimes $[13,75]$. Irrigation at the shooting and anthesis stages can activate the biosynthesis of albumin, globulin, gliadin, and glutenin in grains [61]. However, increasing the irrigation frequency, especially after anthesis, may result in worsened protein quality [60]. For soil containing high moisture, additional nitrogen fertilizers may encourage the improvement of GPC and related processing quality [60]. Because the biosynthesis of protein and starch is differentially regulated by soil moisture [66], the selection of suitable irrigation practices can be used as an agronomic means to achieve the desired protein-based grain quality.

\section{Sowing time}

Different sowing timing provides variations in growth period, grain-filling duration, and days with air temperature that is appropriate for wheat growth. Therefore, adjusting the sowing time has a significant effect on nitrogen assimilation, protein remobilization, and processing quality by regulating the thermal conditions and precipitation, particularly during grain filling [55]. In the Highlands of the Xiaoxingan Mountains $\left(48^{\circ} 52^{\prime} \mathrm{N}\right.$, $125^{\circ} 17^{\prime} \mathrm{E}$; elevation $213 \mathrm{~m}$ ), Heilongjiang, late sowing (mid-May to the first days of June) resulted in increases in GPC (up to 16\%), WGC (to 33\%), SV (to 60\%), and extensibility (to $19 \mathrm{~cm}$ ) for strong-gluten spring wheat varieties. In Lixiahe (Zone IV) $\left(32^{\circ}\right.$ $23^{\prime} \mathrm{N}, 119^{\circ} 26^{\prime} \mathrm{E}$; elevation $5 \mathrm{~m}$ ), Jiangsu, although $30 \%$ of the varieties that are popularly planted in this region are less sensitive to sowing from mid-October to early November; sowing in late October generally produces desired grain qualities with $13.6 \%$ GPC, $8.8 \mathrm{ml} \mathrm{SV}$, and $34.2^{\circ}$ WGC (15). Qionglai $\left(30^{\circ} 25^{\prime} \mathrm{N}\right.$, $103^{\circ} 29^{\prime} \mathrm{E}$, elevation $501.4 \mathrm{~m}$; Zone V) is located in the central part of the Western Sichuan Plain and therefore has distinct basin characteristics. Whereas sowing near October 20 may improve both the grain quality and yields in low-vernal wheat cultivars, of the delay of sowing could avoid low-temperature damage to rapidly developed seedlings of winter wheat that would occur when planted early [54]. In Zones I-III, spring wheat sown during mid-Aril to early May can produce higher GPC and SV than earlysown spring wheat and fall-sown wheat [57, 69]. Spring sowing often leads to a shorter grain-filling period, decreased photo assimilate accumulation, and relatively increased GPC compared to the fall sowing [69]. In brief, the wheat quality of given cultivars can be improved by choosing an appropriate sowing timing.

\section{Planting in target regions favorable for a good expression of particular wheat quality traits}

As $G \times E$ interactions significantly influence the wheat quality and wheat cultivars show responses to key environmental variables in regards to grain protein synthesis and associated processing quality, the selection of the production environments will improve grain quality for certain cultivars [27, 29]. Likewise, genotype selection is crucial for achieving a desired processing quality in a targeted regional environment.

\section{Result}

The effects of soil type and their interaction with local climate (Table 2).

\section{Conclusions}

Wheat breeders routinely use milling and baking quality evaluations as important selection criteria. Breeding programs, however, have inadequate resources to evaluate quality characteristics of large numbers of lines grown across multiple environments. Hence, breeders have little information on quality variation attributable to differential responses of genotypes to Environmental conditions. Environmental conditions are known to have significant influence on end-use quality characteristics of wheat, but the relative magnitude of environmental, genetic, and $G \times E$ effects on quality is unclear. Wheat quality may be improved by breeding

Table 2. Relationships Between Grain Quality and Wheat Variety, Sowing Time and The Environment (F Values) [48].

\begin{tabular}{|c|c|c|c|c|}
\hline Variant factors & GPC (\%) & WGC (\%) & SV & FN (s) \\
\hline Environment & $22.27^{* *}$ & $8.75^{* *}$ & $17.34^{* *}$ & $93.30^{* *}$ \\
\hline Sowing time & 0.00 & 0.00 & 2.00 & 2.18 \\
\hline Variety & $92.51^{* *}$ & $95.32^{* *}$ & $64.94^{* *}$ & $80.83^{* *}$ \\
\hline Environment $\times$ Sowing time & $1.66^{*}$ & 4.40 & $5.27^{* *}$ & 0.50 \\
\hline Environment $\times$ Variety & $5.14^{*}$ & $2.11^{*}$ & $11.70^{* *}$ & $5.26^{* *}$ \\
\hline Sowing time $\times$ Variety & 2.20 & $2.02^{*}$ & $4.94^{*}$ & $3.46^{* *}$ \\
\hline Environment $\times$ Sowing time $\times$ Variety & 1.39 & $2.00^{*}$ & $1.98^{*}$ & 1.29 \\
\hline
\end{tabular}

$*$ and $* *$ are significant at the 0.05 and 0.01 probability levels, respectively. 
elite varieties, improving crop/farming management practices and exploiting the synergism between genotype and the environment. Environmental variables have important effects on wheat grain protein accumulation and processing quality, although wheat quality is a genotype-dependent trait. In general, moderately high temperature, proper soil moisture (resulting from rainfall and irrigation), and sufficient solar radiation may improve wheat quality. Some ecological factors, including soil physiological and chemical properties and geographic latitude, can also affect wheat quality. The conclusions presented in this review may be useful for quality-based wheat production zoning in worldwide.

\section{Future Considerations}

Due to the shortage of high-quality genotypes and the insufficiency of related research, we are unable to achieve reciprocal adaptation between wheat cultivars and environments $[56,76]$. More studies must be conducted at the physiological, biochemical, and molecular levels to draw reliable conclusions about wheat quality. To better choose special cultivar(s) for target growth locations and to enhance the probability of predicting and identifying cultivars with superior grain quality, studies characterizing the genotypic variability in various environments will have to be conducted [71]. The identification and examination of key genetic and environmental components that affect quality and $\mathrm{G} \times \mathrm{E}$ interactions have proven successful in breeding and cultivating good-quality crop cultivars. For example, in regions with excessive rainfall, breeders should pay greater attention to such traits as early maturity to avoid the rainy season in the early summer. Molecular and conventional breeding will be valid means to increase wheat quality and can be aided by the use of highly efficient quality analytical technologies, such as near infrared spectroscopy technology and molecular marker technology for quality-related genes. Mapping the quantitative trait loci (QTL) associated with individual characteristics of grain and flour quality in wheat lines grown under contrasting environmental conditions could potentially be used to genetically control wheat quality $[53,76]$. To analyze the effects of the environment on GPC and related processing quality, the application of crop growth simulation models and forecasting systems would be of considerable value to farmers to grow appropriate genotypes, optimize late-season managements, and predict grain quality for the prospective wheat harvest $[23,45]$. The most extensively used models (AMMI, the analysis of variance, regression analysis, principal components analysis, and the additive main effects and multiplicative interaction) have been proven to be effective platforms for predicting the environmentally induced impacts on grain quality $[29,56]$.

\section{References}

[1]. Altpeter F, Vasil V, SrivastavaV, Vasil IK. Integration and expression of the high-molecular-weight gluteninsubu-nit laxl gene into wheat. Nat Biotech.1996 Sep;14(9):1155-9. PMID: 9631070.

[2]. Anderson OD, Bekes F, Gras P, Kuhl JC, Tam A. Use of a bacterial expression system to study wheat high-molecular-weight (HMW) glutenins and the construction of synthetic HMW-glutenin genes, Royal Austr. Chem. Inst.North Melbourne, Australia. 1996; 195-198.

[3]. Axtord DW, McDermott EE, Redman DG. Note on the sodium dodecyl sulfate test of bread making quality: comparision with pelschenke and Zeleny test. Cereal Chem. 1979;56(6):582-4.

[4]. Chen Y, Wang RD, Kong J, Zhang W, Nie YB. Studies on wheat quality ecology in Xinjiang. Xinjiang AgrSci. 2005; 42:369-376.

[5]. Bekes F. Demonstration of the 2-gram mixograph as a research tool. Cereal
Chem.1992;69:229-30

[6]. Bekes F, Anderson O, Gras PW, Gupta RB, Tam A, Wrigley CW, et al The contributions to mixing properties of 1D HMW glutenin subunits expressed in a bacterial system. InImprovement of cereal quality by genetic engineering. Springer, Boston, MA. 1994; 97-103.

[7]. Bekes F, Gras PW, Gupta RB, Hick-man DR, Tatham AS. Effects of 1Bx2OHMW glutenin on mixing properties. J. Cereal Sci. 1994b; 19: 3-7.

[8]. Bhattacharya M, Corke H. Selection of desirable starch pasting properties in wheat for use in white salted or yellow alkaline noodles. Cereal chemistry (USA). 1996; 73: 721-728.

[9]. Blechl AE. Gene transformation: a new tool for the improvement of wheat. In Wheat Yearbook, Economic Research Service/USDA.1998Mar; 30-32.

[10]. Blechl AE, AndersonOD.Expression of a novel high-molecular-weight glutenin in transgenic wheat. Nat. Biotech.1996 Jul;14(7):875-9. PMID: 9631014.

[11]. Zhong-Min DA, Yan-Ping YI, ZHANG M, Wen-Yang LI, Su-Hui YA, RuiGuo CA, et al. Distribution of starch granule size in grains of wheat grown under irrigated and rainfed conditions. ActaAgronomicaSinica. 2008 May 1;34(5):795-802.

[12]. Diacono M, Castrignanò A, Troccoli A, De Benedetto D, Basso B, Rubino P. Spatial and temporal variability of wheat grain yield and quality in a Mediterranean environment: A multivariate geostatistical approach. Field Crops Research. 2012 May 13;131:49-62.

[13]. Zhong-Min DA, Yan-Ping YI, ZHANG M, Wen-Yang LI, Su-Hui YA, RuiGuo CA, et al. Distribution of starch granule size in grains of wheat grown under irrigated and rainfed conditions. Acta Agronomica Sinica. 2008 May 1; 34(5):795-802.

[14]. United Nations Food and Agriculture Organization. World Food SituationFood Cereal Supply and Demand Brief. Government of Pakistan. Rome. 2009

[15]. Fan J. Effect of Sowing-time on Major Quality Traits of Wheat. Anhui Agricultural Sciences.2003;31(1):23-4.

[16]. Fernandez-Figares I, Marinetto J, Royo C, Ramos JM, Del Moral LG. Amino-acid composition and protein and carbohydrate accumulation in the grain of triticale grown under terminal water stress simulated by a senescing agent. J Cereal Sci. 2000 Nov 1; 32(3): 249- 58.

[17]. Food and Agriculture Organization of the United Nations [Internet]. FAOSTAT;2005. [cited 24 Feb. 2005; verified 14 Oct. 2005]. Available from http://www.fao.org/faostat FAO.

[18]. Fu BX, Sapirstein HD. Fractionation of monomeric proteins, soluble and insoluble glutenin, and relationships to mixing and baking properties. Gluten '96. Royal AustrChemInst, North Melbourne. 1996; 340-4.

[19]. Greenwell P. A starch granule protein associated with endosperm softness in wheat. Cereal Chem.. 1986; 63: 379-80.

[20]. Gupta RB, MacRitchie F. A rapid one-step one-dimensional SDS-PAGE procedure for analysis of subunit composition of glutenin in wheat. Journal of Cereal Science. 1991 Sep 1; 14(2):105-9.

[21]. Ge ZQ. Effects of density and nitrogen interaction on grain yield and quality of weak gluten wheat. Anhui AgrSci Bull. 2011;17:61-4.

[22]. Gil DH, Bonfil DJ, Svoray T. Multi scale analysis of the factors influencing wheat quality as determined by Gluten Index. Field Crops Research. 2011 Jul 18;123(1):1-9.

[23]. Gooding MJ, Davies WP. Wheat production and utilization: systems, quality and the environment. CAB international; Wallingford, UK; 1997.

[24]. Han QX, Guo TC, Wang HC, Wang YH, Yan LY. Effects of soil texture on flag-leaf nitrogen content and grain protein content in winter wheat. J Triticeae Crops; 2007; 27: 677-681.

[25]. Han QX, Liu PX, Wang HC, Yan LY, Guo TC. Qiao-xia HA. Effect of Different Texture Soil on Bulk Weight of Kernels and Some Flour Qualities of Wheat [J]. Journal of Anhui Agricultural Sciences. 2008;28.

[26]. He ZH, Lin ZJ, Wang LJ, Xiao ZR Wan FS, Zhuang QS. Classification on Chinese wheat regions based on quality. SciAgric Sin. 2002; 35: 359-364.

[27]. He ZH, Yang J, Zhang Y, Quail KJ, Pena RJ. Pan bread and dry white Chinese noodle quality in Chinese winter wheats. Euphytica. 2004 Feb 1;139(3):257-67.

[28]. Högy P, Fangmeier A. Effects of elevated atmospheric $\mathrm{CO} 2$ on grain quality of wheat. Journal of Cereal Science. 2008 Nov 1;48(3):580-91.

[29]. Hristov N, Mladenov N, Djuric V, Kondic-Spika A, Marjanovic-Jeromela A, Simic D. Genotype by environment interactions in wheat quality breeding programs in southeast Europe. Euphytica. 2010 Aug 1;174(3):315-24.

[30]. Hu X, Zhou G, Wu L, Lu W, Wu L, Li J, Wang S, Song J, Yang X, Wang B. Variation of wheat quality in main wheat-producing regions in China. Acta Agronomica Sinica. 2009;35(6):1167-72. a. Huang S. A look at noodles in China. Cereal foods world (USA). 1996; 41: 199-204.

[31]. Jin SB. The Ecological Theory and Practices in Wheat Planting. Zhejiang Science and Technology Press, Hangzhou, China. 1992:167-81. 
[32]. Jing Q, Jiang D, Dai T, Cao W. Effects of genotype and environment on wheat grain quality and protein components. Ying yong sheng taixuebao= The journal of applied ecology. 2003 Oct;14(10):1649-53.

[33]. Kimball BA, Morris CF, Pinter PJ, Wall GW, Hunsaker DJ, Adamsen FJ, et al. Elevated $\mathrm{CO} 2$, drought and soil nitrogen effects on wheat grain quality. New Phytologist. 2001 May 1;150(2):295-303.

[34]. Kong L, Cao C, Wang J, Zhao B, Zhao Z. Effects of soil basic fertility and nitrogen application on grain yield and quality of strong gluten wheat. Chinese agricultural science bulletin. 2005;21(7):248-51.

[35]. Konik CM, Mikkelsen LM, Moss R, Gore PJ. Relationships between physical starch properties and yellow alkaline noodle quality. Starch-Stärke. 1994;46(8):292-9.

[36]. Lan J. Application of biotechnology in the improvement of wheat quality traits. Heilongjiang Agr Sci. 2008;5:7-11.

[37]. Li H, Zhang Y, Wu X, Li Z. Determination and evaluation on the main quality characters of wheat germplasm resources in China. Zhongguonongyekexue. 1995; 28(5): 29-37.

[38]. Liu JH, Hu SA, Zeng HB. Study on somaclonal variation in wheat quality improvement. J Northeast-AgricUniv. 1997; 28: 334-339.

[39]. Kong L, Cao C, Wang J, Zhao B, Zhao Z. Effects of soil basic fertility and nitrogen application on grain yield and quality of strong gluten wheat. Chinese agricultural science bulletin. 2005; 21(7): 248-51

[40]. MacRitchie F. Role of polymeric proteins in flour functionality. In Wheat kernel proteins: molecular and functional aspects, Universitadeglistudidella $T$ uscia, Bitervo, Italy. 1994; 145-150.

[41]. Miller RA, Hoseney RC. Factors in hard wheat flour responsible for reduced cookie spread. Cereal chemistry. 1997 May;74(3):330-336.

[42]. Miller BS, Afework S, Pomeranz Y, Booth GD. Measuring the hardness of wheat. Cereal Foods World, USA. 1982. 27: 61-64.

[43]. Nagao S, Ishibashi S, Imai S, Sato T, Kanbe Y, Kaneko Y, et al. Quality characteristics of soft wheats and their utilization in Japan. II. Evaluation of wheats from the United States, Australia, France and Japan. Cereal Chem.. 1977;54:198-204

[44]. Naeem HA, Paulon D, Irmak S, MacRitchie F. Developmental and environmental effects on the assembly of glutenin polymers and the impact on grain quality of wheat. J Cereal Sci. 2012 Jul 1;56(1):51-7.

[45]. Pan J, Dai T, Jiang D, Zhu Y, Cao W. An ecological model forpredicting grain protein content in winter wheat. Zhongguonongyekexue. 2005;38(4):684-91.

[46]. Pan J, Jiang D, Dai T, Lan T, Cao W. Variation in wheat grain quality grown under different climatic conditions with different sowing dates. ActaPhytoecologicalSinica. 2005;29(3):467-73.

[47]. Peck AW, McDonald GK, Graham RD. Zinc nutrition influences the protein composition of flour in bread wheat (Triticumaestivum L.). Journal of Cereal Science. 2008 Mar 1;47(2):266-74.

[48]. Pan J, Jiang D, Dai T, Lan T, Cao W. Variation in wheat grain quality grown under different climatic conditions with different sowing dates. Acta Phytoecological Sinica. 2005; 29(3): 467-73.

[49]. Rharrabti Y, Villegas D, Royo C, Martos-Núñez V, Del Moral LG. Durum wheat quality in Mediterranean environments: II. Influence of climatic variables and relationships between quality parameters. Field Crops Research. 2003 Jan 20;80(2):133-40.

[50]. Shi SB, Ma L, Shi QH, Liu X, Chen LM, Liu JX, Wang ZL. Effect of nitrogen application timing on protein constitutes and its dynamic change in wheat grain. Plant NutrFert Sci. 2005;11:456-60.

[51]. Shi Y, Zhang Y, Yu Z. Effects of nitrogen fertilizer application on protein components contents and processing quality of different wheat genotypes. Plant Nutrition and Fertilizer Science. 2010;16(1):33-40.

[52]. Slafer GA, Satorre EH. An introduction to the physiological-ecological analysis of wheat yield. Wheat: Ecology and physiology of yield determination. 1999 May 6:3-12.

[53]. Sun X, Marza F, Ma H, Carver BF, Bai G. Mapping quantitative trait loci for quality factors in an inter-class cross of US and Chinese wheat. Theoretical and applied genetics. 2010 Mar 1;120(5):1041-51

[54]. Tan FQ, Xuan SQ, Fan XJ, Ren ZL (2008) Effects of sowing time on yield and quality of winter wheat (TriticumaestivumL.) in Sichuan Basin. J Anhui Agr Sci.2008; 36:14922-14924

[55]. Yong-Lu TA, Yuan-Qi WU, Hua-Zhong ZH, Chao-Su LI, Sheng-Rong LI, ZHENG CG, Ji-Chao YU, Xiu-Fang YU. Quality performance and stability of main wheat cultivars in Sichuan Province. ActaAgronomicaSinica. 2010 Nov 1;36(11):1910-20

[56]. Wang CY, Ouyang G, Ma DY, Guo TC, Zhu YJ, Cui JM, et al. Effects of sowing date on quality traits and starch pasting properties in different genotypes of wheat cultivars. ActaAgricBoreali-Sin. 2005;20:49-52.

[57]. Wang FH, Zhao JS. The grain yield and quality of different types of winter wheat in different ecological zones. J LaiyangAgric Univ. 1997;14:100-4.

[58]. Wang H, Li Z, Ma Y, Zhao C, Liu Z, Ning T, Jiao N. Study on differences in quality traits of the high-quality wheat in different soil types. Chinese agricultural science bulletin. 2005;21(7):143-4.

[59]. WANG LH, SUN B, WANG XZ, CAO WM, PEI RJ, CHAO JL, WANG LQ, LIU ST. Effect of Potassium Application on Grain Yield and Quality of Strong Gluten Wheat Grown in Fluvo-Aquic Soil [J]. Journal of Triticeae Crops. 2008; 28:466-470.

[60]. Wang X, He M, Li F, Liu Y, Zhang H, Liu C. Coupling effects of irrigation and nitrogen fertilization on grain protein and starch quality of strong-gluten winter wheat. Frontiers of Agriculture in China. 2008 Sep 1;2(3):27480 .

[61]. Wang XY, Yu ZW. Effects of irrigation on nitrogen metabolism and grain quality in winter wheat. Acta Bot Boreal-Occident Sin. 2009;29:1415-20.

[62]. Weegels PL, Hamer RJ, Schofield J1. Functional properties of wheat glutenin. Journal of Cereal Science. 1996 Jan 1;23(1):1-7.

[63]. Wu D, Cao G, Qiang X, Kou B. Relationship between ecological height and wheat quality. Journal of Triticeae Crops. 2003;23(2):47-51.

[64]. Xie Y, Zhu Y, Zhu X, Guo T, Wang C, Tian W. Effects of sulphur application on grain yield and processing quality in medium-gluten wheat. ActaAgronomicaSinica. 2009;35(8):1532-8.

[65]. Xie Z, Jiang D, Cao W, Dai T, Jing Q. Relationships of endogenous plant hormones to accumulation of grain protein and starch in winter wheat under different post-anthesis soil water statusses. Plant growth regulation. 2003 Oct 1;41(2):117-27.

[66]. Yan J, Zhang Y, He ZH. Investigation on paste property of Chinese wheat. ScientiaAgriculturaSinica. 2001;34:9-13.

[67]. Yang LL, Liu H, Lu ZF. Effects of cultural and environmental conditions on the grain quality of wheat. Cereal Crop. 2008;9:77-80.

[68]. Yao D, Li B, Liang R, Liu G. Effects of wheat genotypes and environments to starch properties and noodle quality. Journal of China Agricultural University. 2000;5(1):63-8

[69]. Yan-rong YA, Xiu-ling JI, Rui-kun MA, Quan-guo ZH, Yan-ru FE, A-li HU. Stability variation and regional climatic impact on quality of highgluten wheat cultivars in central-south region of Hebei. ActaAgriculturaeBoreali-Sinica. 2006:S2;23-28.

[70]. Zhang HH, Zhang YQ, Zhang JP, Jia ZK.Effect of nitrogen, phosphorus, potassium fertilizer application on yield and quality of strong gluten gluten wheat. J Triticeae Crops;2008; 28:457-460.

[71]. Zhang X, Guo T, Zhu Y, Li Z, Wang C, Ma D. Environmental effects of different latitudes on starch paste property of three types of gluten wheat in He'nan Province. ActaEcologicaSinica. 2004;24(9):2050-5.

[72]. Zhang XL, Wang ZQ, Guo TC, Wang CY, Zhu YJ, Li ZQ. Effect of latitude on grain protein concentration of winter wheat. Chinese App1 Eco1. 2008;19:1727-32.

[73]. Zhang Y, Cao C, Zhao Z, Qiao Y, Liu Y, Zhang S. Effect of nitrogen on yield and quality of different types of wheat. Journal of Triticeae Crops. 2009;29(4):652-7.

[74]. Zhao CX, Du JZ, Wang YF, Zhou H, Wang RY (2009a) Effects of nitrogen and potassium on yield and quality of strong gluten wheat. Chinese AgrSci Bull. 2009a; 25:156-160.

[75]. Zhao CX, He MR, Wang ZL, Wang YF, Lin Q. Effects of different water availability at post-anthesis stage on grain nutrition and quality in strong-gluten winter wheat. CRBiol. 2009; 332(8):759-64. PubMed PMID: 19632660

[76]. Zhao L, Zhang KP, Liu B, Deng ZY, Qu HL, Tian JC. A comparison of grain protein content QTLs and flour protein content QTLs across environments in cultivated wheat. Euphytica. 2010;174(3):325-35.

Special Issue on: "Food and Public Health"

\section{Theme Edited by:}

Assaf A. Abdelghani, Tulane University School of Public Health and Tropical Medicine, USA. E-mail ID: assafa@tulane.edu 